\title{
Stability behavior of non-surfactant water-in- diesel emulsion fuel using microscopic observation
}

\author{
Siti Amiliyana Norazni ${ }^{1}$, Wira Jazair Yahya ${ }^{1,}{ }^{*}$, Ahmad Muhsin Ithnin $^{1}$, Hasanuddin Abd Kadir $^{1}$, Ili \\ Fatimah Abd Razak ${ }^{1}$, Nadia Dayana Bahar ${ }^{1}$, Dhani Avianto Sugeng ${ }^{1}$, and Nur Atiqah Ramlan ${ }^{1}$ \\ ${ }^{1}$ Vehicle System Engineering, Malaysia-Japan International Institute of Technology, Universiti \\ Teknologi Malaysia, Jalan Semarak, 54100 Kuala Lumpur, Malaysia
}

\begin{abstract}
Water-in-diesel emulsion fuel (W/D) is considered to be a potential alternative fuel that can reduces nitrogen oxides $\left(\mathrm{NO}_{\mathrm{x}}\right)$ and particulate matter (PM). W/D is normally produced with addition of surfactant to prolong its stability. However, the dependency on surfactant leads to higher production cost. A concept that can eliminate dependency on the surfactant was introduced by strong mixing concept and direct supply the non-surfactant W/D to a diesel engine. Therefore, the objective of this study is to investigate the stability behavior of non-surfactant W/D using microscopic observation. Water and diesel fuel were mixed using a combination of high-shear mixer and an ultrasonic transducer. The amount of water injected into the system are $5 \%$ and $10 \%$ by volume, which were labelled as E5 and E10 respectively. The produced non-surfactant W/D was then placed into a petri dish for microscopic observation. The results showed that the average diameter of water droplets observed in E5 and E10 at sedimentation stage were 15.38 and $22.41 \mu \mathrm{m}$ respectively. The stability period of E5 and E10 before it sediment were 25 and 67 seconds correspondingly. Overall, it is observed that microscopic observation is a reliable approach to determine the stability behavior of non-surfactant W/D.
\end{abstract}

\section{Introduction}

The interest in water-in-diesel emulsion fuel (W/D) for diesel engine application has been growing worldwide as it is regarded as an effective way to reduce the harmful pollutants such as nitrogen oxide $\left(\mathrm{NO}_{\mathrm{x}}\right)$ and particulate matter $(\mathrm{PM})$ simultaneously. Moreover, it also improves the combustion efficiency [1-4]. An emulsion is a mixture of two or more liquids that are immiscible in nature where one present as droplet, or the dispersed phase throughout another liquid known which acts as the continuous phase [3]. Emulsion is produced with the assistance of some external means, either by mechanical or ultrasonic agitation; and eventually, with an addition of surfactant to help bind both diesel and water together as one solution [5-8]. The mechanical homogenizing machine is the most used emulsifying device in emulsion preparation; it stirs up the mixture of continuous and

\footnotetext{
* Corresponding author: wira@utm.my
} 
dispersed phase with the presence of surfactant [8]. Furthermore, there are also applications using ultrasonic agitation to produce emulsified fuel. The ultrasonic waves cause cavitation which creates alternating positive and negative pressure waves to form a strong mixing effect. It has been proven that the combination of mechanical and ultrasonic components in producing W/D yields small water droplet size [7].

The surfactant is required in the formation of W/D to lower the interfacial tension between the dispersed phase and the continuous phase while altogether to stabilize the water droplet phase within the diesel fuel phase to avoid coalescence [9]. Surfactant, also known as surface-active agent is a substance that contain both polar and non-polar groups in their molecules. Hydrophilic surfactants have more attraction to polar liquids such as water, in contrast to lipophilic surfactants which are more soluble in nonpolar liquids such as oil [8]. In W/D, the most commonly used surfactants by researchers are SPAN 80 and TWEEN 80, which are added to a certain percentage to achieve emulsion stability[10]. M.T. Ghannam et. al [9] reported that the separation time of water and diesel (i.e. destabilization of W/D) is dependent on water percentage. The increase of water percentage reduces the W/D stability, in other words, the separation time of water droplets phase from emulsion decreases. The stability of W/D relies on two factors which are the existence of surfactant around the surface droplets and coalescence mechanism [11]. In diesel engine, if the W/D is destabilized during storage or while the engine is in operation, it may cause engine failure and damage other components.

Utilizing the surfactant to a great large scale W/D production is not viable as the price of the surfactant is very high. This hinders the commercialization of W/D in the real-world applications. Therefore, with the motivation to utilize the W/D without using surfactant or so called non-surfactant W/D, a novel concept of a mixing system was introduced in previous study $[12,13]$. The idea of the system was to focus on the production of W/D through an in-line mixing system by continuously mixing diesel fuel and water, then directly supplies the produced W/D to the engine. This concept of mixing system is known as Real-Time Emulsion Fuel Supply System (RTES). Through this concept, the need of W/D with extended stability period is not relevant anymore, and the addition of the surfactant in W/D can be omitted. The W/D produced from the RTES is thermodynamically unstable, but it needs to stay stable before it is injected into the engine. In previous studies, there are several methods of determining emulsion stability have been proposed such as droplet size analysis, measurements of the physical properties of emulsion [14], accelerated test [15], turbidity ratio measurement [16] and bottle test method. With the latter, the prepared emulsion is placed into beaker/bottle and the time for the emulsion to destabilize is recorded (layer of diesel and water is observed) $[9,15]$. However, none of the researchers use the microscopic approach to explaining the stability behavior of nonsurfactant W/D.

Therefore, the objective of this paper is to investigate the stability behavior of nonsurfactant W/D produced by RTES in term of droplet size measurement and stability period by microscopic observation. In the experimental work, a detailed analysis of the stability behavior was conducted with a variety of $5 \%$ and $10 \%$ water content.

\section{Experimental setup}

The experimental procedures comprised of two stages where the first stage was the preparation of the non-surfactant W/D with 5 and 10 volumetric percent of water using a strong mixing system, RTES. The non-surfactant W/D with $5 \%$ and $10 \%$ of water were labeled as E5 and E10 respectively. The second stage was the stability behavior analysis of the non-surfactant W/D, carried out by using a microscope. In this analysis, observations of the water droplet size and the duration of W/D to sediment were performed. The produced 
non-surfactant W/D need to stay intact or in other words, to be stable for at least 3 seconds, which is the time needed for the fuel travel from the pump to reach the engine. Figure 1 below shows the non-surfactant W/D preparation process and the test setup.

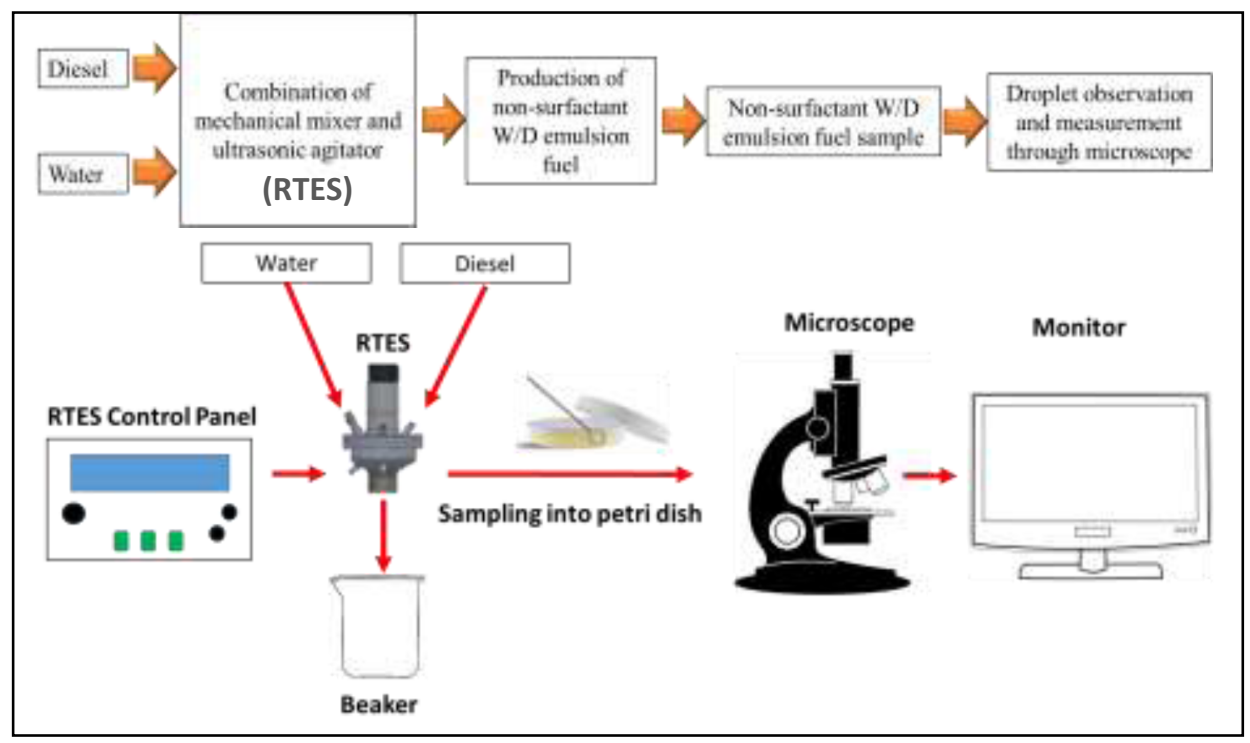

Fig. 1. Non-surfactant W/D preparation and test setup.

\subsection{Preparation of water-in-diesel emulsion fuel (W/D)}

For the preparation of E5 and E10, Malaysia grade 2 diesel fuel (D2) was mixed with water using RTES, which is a combination of high shear mixer with a constant motor speed of $1400 \mathrm{rpm}$ and ultrasonic transducer with a frequency of $50 \mathrm{kHz}$. As shown in Figure 1, the diesel fuel flowed from the fuel tank and water was injected into the mixing chamber. Both liquids were mixed with high shear force and acoustic wave to produce W/D. Here, no surfactant was involved in the proses. The amount of water $(5 \%$ and $10 \%)$ was regulated by a controller placed in the RTES control panel. RTES then supplied the non-surfactant W/D emulsion continuously and instantaneously. Table 1 below shows the properties of diesel fuel, used in the experiment.

Table 1. Specifications of Malaysia grade 2 diesel fuel [2].

\begin{tabular}{|c|c|}
\hline \multicolumn{2}{|c|}{ Properties } \\
\hline Cetane index & 54.6 \\
\hline Viscosity at $40^{\circ} \mathrm{C}, \mathrm{cSt}$ & 4.642 \\
\hline Density at $15^{\circ} \mathrm{C}, \mathrm{kg} / \mathrm{L}$ & 0.8538 \\
\hline Carbon, wt $\%$ & 84.1 \\
\hline Calorific value, $\mathrm{MJ} / \mathrm{kg}$ & 45.280 \\
\hline Total sulphur, mass $\%$ & 0.28 \\
\hline Flash point, ${ }^{\circ} \mathrm{C}$ & 93 \\
\hline
\end{tabular}

In the sampling process, the non-surfactant W/D was transferred into a graduated beaker. Then, a small portion of the fuel was placed into a petri dish for observation and 
measurement. While the behavior of the fuels were recorded by a microscope, the destabilization process of E5 and E10 emulsion process were also taken in video format with a duration of two minutes. For this purpose, a super resolution digital microscope with a magnification range of 100 to 1000 times was used. The specifications of the microscope are listed in Table 2.

Table 2. Specifications of the digital microscope.

\begin{tabular}{|c|c|}
\hline \multicolumn{2}{|c|}{ Properties } \\
\hline Model & $\begin{array}{c}\text { KEYENCE VHX-200E digital } \\
\text { microscope, equipped with VH-Z100R } \\
\text { zoom lens }\end{array}$ \\
\hline Magnification range & 100 to 1000 times \\
\hline Image size (pixels per image) & $1600 \times 1200$ \\
\hline Video size (frames per second) & 15 \\
\hline
\end{tabular}

\section{Results and discussion}

As shown in Figure 2, the water droplet size gradually increased proportionally with time. At 10 seconds, the average diameter of water droplet size in E10 was $15.38 \mu \mathrm{m}$ and the water droplets were moving freely at this stage. An emulsion is characterized as thermodynamically unstable; thus, the repulsive force between the droplets become weaker as time elapses. Ghannam et al. defined that the stability of the W/D by measuring the amount of water separated over time [9]. However, in this analysis, the stability of W/D ended when water layer began to appear at the bottom of the beaker. In other words, the $\mathrm{W} / \mathrm{D}$ is described as destabilize when the sedimentation process occurs. As illustrated in Figure 2, after 25 seconds, the droplets became more attracted to each other, and the average droplet diameter reached $24.41 \mu \mathrm{m}$, which was bigger than previous droplet size, at $15.38 \mu \mathrm{m}$. The larger water droplet started to sink to the bottom of the beaker, which signified the sedimentation process to begin after the $25^{\text {th }}$ second.

Figure 3 shows the sequence of sedimentation process of the same E10 emulsion, recorded after two minutes of mixing. It was evident that the size of water droplets become bigger with time. In the destabilization process of W/D emulsion, initially, the droplets underwent a flocculation process, where the water droplets move toward each other. This was due to the weaker repulsive bond between the droplets. They then formed three dimensional (3-D) clusters in which multiple droplets were bounded and separated only by a thin-film. The thickness of the thin-film was then slowly receding as it dictated by the Van der Waals force and when it reached its critical limit, the film broke, and the droplets formed larger water droplet (i.e. coalescence). Finally, followed by the sedimentation process, where large water droplets sank to the bottom of the beaker due to the density difference between water and diesel fuel. The process continued until the water was completely separated from diesel fuel and the W/D turned into two distinct layers.

The stability experiment for E5 was conducted under the same experimental condition as E10. Similar behavior and pattern with E10 was observed, where at the initial stage, the droplets were freely moving in the emulsion continuous phase. After 67 seconds, the sedimentation process occurred. Here, the average water droplet size observed in E5 is 9.54 $\mu \mathrm{m}$ which was smaller compared to the droplet size found in E10 $(22.41 \mu \mathrm{m})$. This was because the amount of water in E5 injected into the system was less than in E10. In contrast, the sedimentation process in E5 takes 2.68 times longer than in E10. While in E5, it occurred at 67 seconds, in E10, it took place at 25 seconds. This implied that nonsurfactant W/D with higher water percentage reached sedimentation stage faster compared 
to one with lesser water percentage. Figure 4 shows the water droplets of E5 after 15 seconds of mixing, at a magnification of $1000 x$.

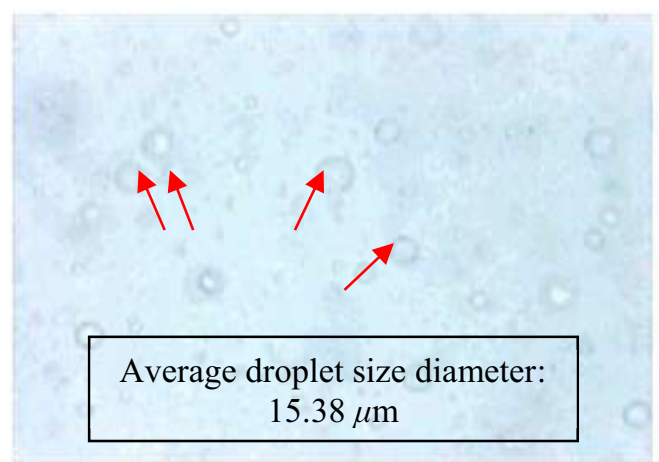

a) $10 \mathrm{~s}$

\section{c) $50 \mathrm{~s}$}

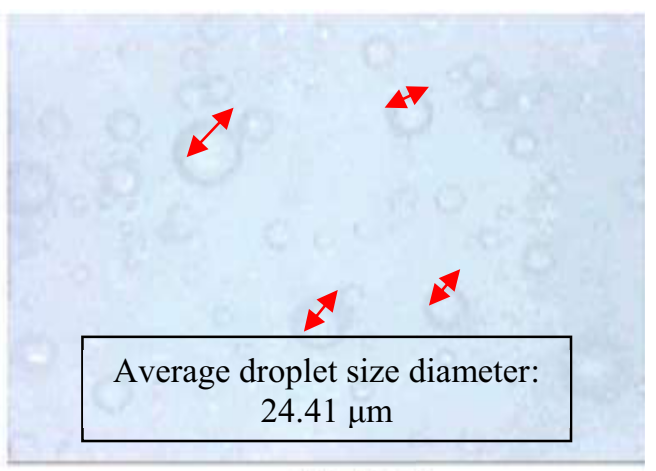

b) $25 \mathrm{~s}$

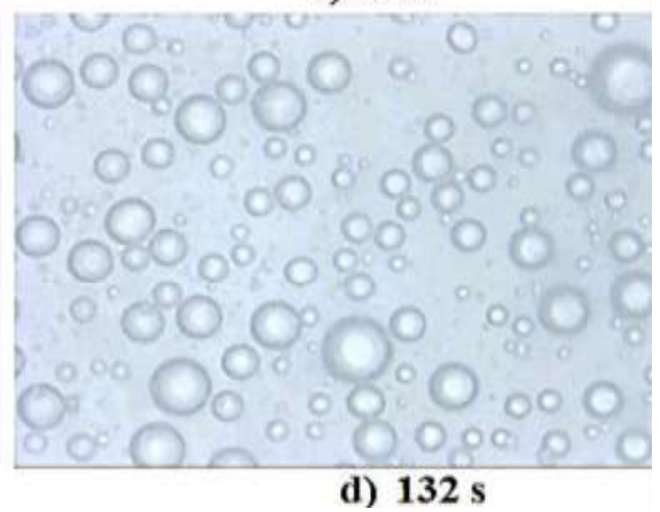

Fig. 2. The sequence of water droplet size in E10 emulsion.(1000x magnification).

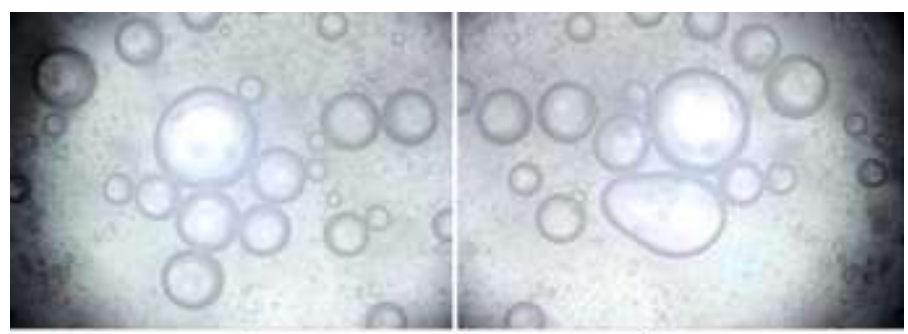

a)

b)

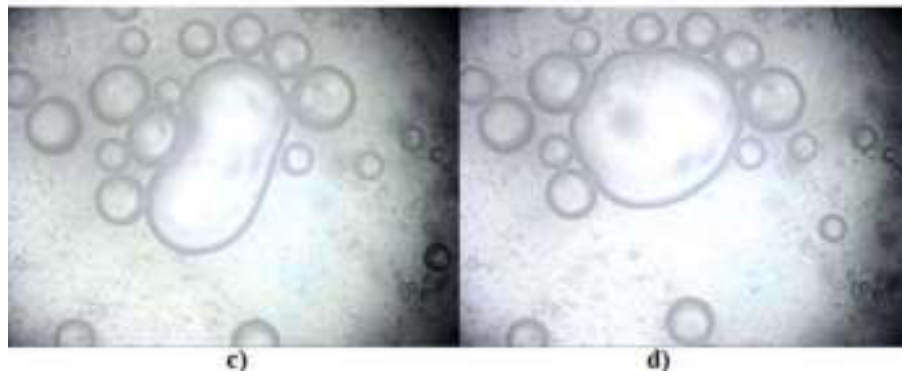

Fig. 3. The sequence of the water droplets destabilization behavior in E10 after 2 minutes of mixing. (100x magnification). 


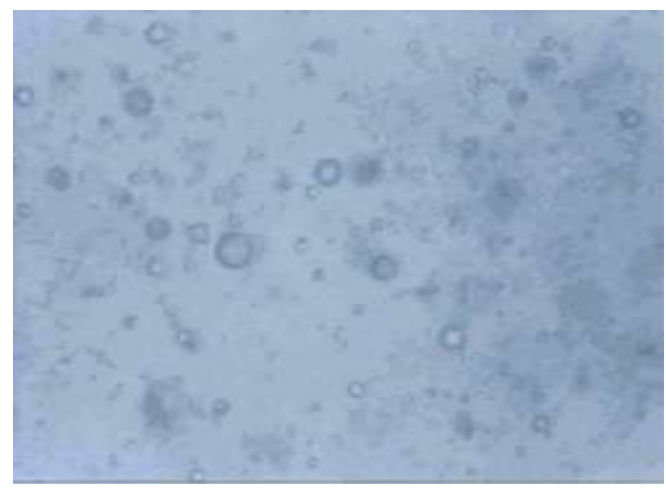

Fig. 4. Water droplet in E5 after 15 seconds of mixing.(1000x magnification).

\section{Conclusions}

This study highlights the stability behavior of non-surfactant W/D produced by a strong mixing system, RTES. Based on the experimental results, the average droplet size diameter of E5 and E10 at sedimentation stage was $9.54 \mu \mathrm{m}$ and $22.41 \mu \mathrm{m}$ respectively. Higher water percentage influence the droplet size and the stability period of non-surfactant W/D. From the observation, the stability period of E5 before reach the sedimentation stage was 67 seconds, while in E10, it was 25 seconds. This shows that both E5 and E10 are stable and exceeded the time it takes for the fuel from the pump to reach the engine.

Overall, it is observed that the evaluation of non-surfactant W/D stability behavior using microscopic observation technique is a reliable method. The characteristic of nonsurfactant W/D that has been analyzed make it a potential alternative fuel which can be used in diesel engine.

The authors would like to express their appreciation to the Centre for Low Carbon Transport, (UTM) and Malaysia-Japan International Institute of Technology (MJIT) for the financial and technical support.

\section{References}

1. A. M. A. Attia and A. R. Kulchitskiy, "Influence of the structure of water-in-fuel emulsion on diesel engine performance," Fuel, vol. 116, pp. 703-708, Jan. (2014).

2. A. M. Ithnin, M. A. Ahmad, M. A. A. Bakar, S. Rajoo, and W. J. Yahya, "Combustion performance and emission analysis of diesel engine fuelled with water-in-diesel emulsion fuel made from low-grade diesel fuel," Energy Convers. Manag., vol. 90, pp. 375-382, (2015).

3. A. Alahmer, J. Yamin, A. Sakhrieh, and M. A. Hamdan, "Engine performance using emulsified diesel fuel," Energy Convers. Manag., vol. 51, no. 8, pp. 1708-1713, Aug. (2010).

4. A. Lif and K. Holmberg, "Water-in-diesel emulsions and related systems," $A d v$. Colloid Interface Sci., vol. 123-126, pp. 231-239, (2006).

5. C.-Y. Lin and K.-H. Wang, "Effects of an oxygenated additive on the emulsification characteristics of two- and three-phase diesel emulsions," Fuel, vol. 83, no. 4-5, pp. 507-515, Mar. (2004).

6. C.-Y. Lin and L.-W. Chen, "Emulsification characteristics of three- and two-phase 
emulsions prepared by the ultrasonic emulsification method," Fuel Process. Technol., vol. 87, no. 4, pp. 309-317, Apr. (2006).

7. C.-Y. Lin and L.-W. Chen, "Comparison of fuel properties and emission characteristics of two- and three-phase emulsions prepared by ultrasonically vibrating and mechanically homogenizing emulsification methods," Fuel, vol. 87, no. 10-11, pp. 2154-2161, Aug. (2008).

8. C.-Y. Lin and K.-H. Wang, "The fuel properties of three-phase emulsions as an

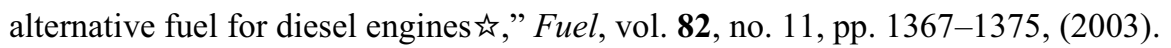

9. M. T. Ghannam and M. Y. E. Selim, "Stability behavior of water-in-diesel fuel emulsion,” Pet. Sci. Technol., vol. 27, no. 4, pp. 396-411, (2009).

10. B. K. Debnath, U. K. Saha, and N. Sahoo, "A comprehensive review on the application of emulsions as an alternative fuel for diesel engines," Renew. Sustain. Energy Rev., vol. 42, pp. 196-211, (2015).

11. P. Sherman and P. Becher, "Encyclopedia of emulsion technology," New York P. Becker ed, (1983).

12. N. A. binti Mazlan, H. A. Kadir, Z. Mohamad, and W. J. Yahya, "Requirement for Real-Time Water Emulsion Fuel Supply System (RTES) Concept Design," in A-DEWS 2015: Design Engineering in the Context of Asia, Asian Design Engineering workshop, 29th-30th October 2015, The Hong Kong Polytechnic University, (2015).

13. W. J. Yahya, A. M. Ithnin, H. Noge, and T. Koga, "Determination of Characteristics for Real-Time Water Emulsion Fuel Supply System (RTES) Concept," in A-DEWS 2015: Design Engineering in the Context of Asia, Asian Design Engineering workshop, 29th-30th October 2015, The Hong Kong Polytechnic University, (2015).

14. T. M. Dreher, J. Glass, A. J. O'Connor, and G. W. Stevens, "Effect of rheology on coalescence rates and emulsion stability," AIChE J., vol. 45, no. 6, pp. 1182-1190, (1999).

15. T. Förster, F. Schambil, and W. Von Rybinski, "Production of fine disperse and longterm stable oil-in-water emulsions by the phase inversion temperature method," $J$. Dispers. Sci. Technol., vol. 13, no. 2, pp. 183-193, (1992).

16. M.-G. Song, S.-H. Cho, J.-Y. Kim, and J.-D. Kim, "Novel evaluation method for the water-in-oil (W/O) emulsion stability by turbidity ratio measurements," Korean J. Chem. Eng., vol. 19, no. 3, pp. 425-430, (2002).

17. A. K. Hasannuddin, M. I. Ahmad, M. Zahari, S. S. Mohd, A. B. Aiman, S. A. Aizam, and J. Y. Wira, "Stability Studies of Water-in-Diesel Emulsion," in Applied Mechanics and Materials, (2014), vol. 663, pp. 54-57. 